\title{
Influence of Trimetazidine on Refractory Period of Isolated Rat Cardiac Muscle
}

\author{
Jiro Sugimoto, Seiichi Yuasa, Masayasu Suzuki \\ and Mitsuhiro Nagata* \\ Department of Pharmacology, Kansai Medical University \\ Moriguchi, Osaka 570 Japan \\ *Department of Pharmacology, Kochi Medical School, \\ Nangoku City, Kochi 781-51 Japan
}

(Received for publication September 29, 1987)

Key words : trimetazidine, refractory period, rat cardiac muscle

\begin{abstract}
Summary
Isolated rat atrial and papillary muscles were kept in a Locke's solution aerated with $100 \%$ oxygen at $30^{\circ} \mathrm{C}$, of which refractory period was measured by using Govier's double stimulus method. Changes of the refractory period were examined when the temperature of the medium was changed from $30^{\circ} \mathrm{C}$ to 25 or $40^{\circ} \mathrm{C}$ and oxygen concentraton in the aeration gas from $100 \%$ to $60,40,20$ or $10 \%$ by replacing the oxygen by nitrogen. In the case in which the medium was aerated with $100 \%$ oxygen gas, the refractory period of the atrial and papillary muscles was lengthened when the temperature was lowered from 30 to $25^{\circ} \mathrm{C}$, and was shortened when it was raised from 30 to $40^{\circ} \mathrm{C}$. Each refractory period generally shortened with reducing the oxygen concentration in aeration gas : it was most marked when the atrial muscle was kept at 25,30 or $40^{\circ} \mathrm{C}$ and when the papillary muscle was kept at $40^{\circ} \mathrm{C}$; and not so marked when the papillary muscle was kept at 25 or $30^{\circ} \mathrm{C}$. By the presence of trimetazidine $[0.0001$ and $0.001 \%(\mathrm{w} / \mathrm{v})$, i. e., 0.003 and $0.03 \mathrm{mM}]$ in the medium, the shortening of the refractory period induced by the reduction of oxygen concentration was prevented in atrial muscle kept at 25,30 or $40^{\circ} \mathrm{C}$ and in papillary muscle kept at $40^{\circ} \mathrm{C}$; although the shortening of the refractory period was not so marked in papillary muscle kept at 25 or $30^{\circ} \mathrm{C}$, the drug caused it longer than value obtained in the muscle aerated by $100 \%$ oxygen gas. The results suggest a new possible application of trimetazidine to the clinical field, as no serious side effect of the drug has been reported in spite of its wide clinical use as an anti-anginal drug in this country.
\end{abstract}




\section{Introduction}

Since Schmitt ${ }^{1)}$ introduced trimetazidine as an anti-anginal drug, Fujita ${ }^{2)}$ and the authors 3-6) have reported various pharmacological actions. As the drug's actions are so unique, that we have been unable to find a drug with pharmacological actions similar to those of trimetazidine. That is, the drug prevents the suppression of spontaneous contractions in isolated guinea-pig atria caused by the effect of a potassium-free Locke's solution, by a toxic dose of strophanthin-G or by a low temperature medium. The drug also prevents the changes of spontaneous contractions induced by electrical stimulation or by nicotine. Although an exact mechanism of the drug hasn't been clarified yet, the mode of action is tentatively presumed to be due to some kind of "membrane stabilizing effect" with regards to cardiac muscle. Pharmacologically, "membrane stabilizing effect" means an effect of a drug which shows very little influence on the normal function of a tissue but gives an influence on the abnormal function caused by physiological or chemical disturbance such as unusual low temperature or a low potassium medium. The drug, which has a marked effect of this kind, is few. The authors had already reported that trimetazidine increases the refractory period of cardiac muscle though in animal experiments, but the drug effect was so weak that it required very much dose such as more than $0.01 \%(\mathrm{w} / \mathrm{v})$. Thereafter, we have searched for actions of the drug which can be observed at lower concentrations, and, in the present study, found that trimetazidine has a remarkable effect to lengthen the refractory period of isolated rat cardiac muscle when the preparation was kept in a condition of oxygen insufficiency. As the effect was shown in a concentration of 0.0001 or $0.001 \%(\mathrm{w} / \mathrm{v})$, we introduce the newly found effect of trimetazidine which suggests a possible application of the drug to the clinical field.

\section{Matreials and Methods}

Male adult rats weighing 350 to $450 \mathrm{~g}$ were killed by severing the common carotid artery. Immediately thereafter, the heart was excised and a left atrium and two papillary muscles were isolated and suspended in an organ bath containing Locke's solution saturated with pureoxygen, at $30^{\circ} \mathrm{C}$ and $\mathrm{pH} 7.3$ to 7.5 . The constituents (mM) of the Locke's solution used were $\mathrm{NaCl} 154, \mathrm{KCl} 5.6, \mathrm{CaCl}_{2}$ 1.6, $\mathrm{NaHCO}_{3} 8.3$ and glucose 5.5, in distilled water. Contractions of the tested muscle were elicited by electrical stimulation with an electronic stimulator (Nihonkohden SEN-3201, Tokyo). The stimuli were twice the threshold intensity, with a pulse duration of $5 \mathrm{msec}$ (for atrial muscle) or $10 \mathrm{msec}$ (for papillary muscle) and a frequency of $4 \mathrm{~Hz}$. The stimulation was given to the preparation through a pair of electrodes $(0.5 \mathrm{~mm}$ of diameter and $5.0 \mathrm{~mm}$ of length), which were placed as closed as possible to the preparation. The contraction of preparation was recorded by use of strain gauges and pen-writing oscillo- 
$S-20$

graphs (Sanei-Sokki Ul-2 and AS-13,, Tokyo).

Stimulation was begun immediately after the preparation was set in an organ bath, and the refractory period was determined $120 \mathrm{~min}$ after the beginning of stimulation. The contraction usually reached equilibrium within $30 \mathrm{~min}$. To determine the refractory period of the preparation, the double stimulus method of Govier ${ }^{7)}$ was used : additional, test stimuli with characteristics identical to those of the driving stimulation were given at intervals of 10 to $250 \mathrm{msec}$ after each driving stimulus. When the interval between the driving and test stimuli was shorter than the refractory period of the preparation, no contractile response to the test stimulus was observed. The interval was gradually increased, until contractil responses to the test stimuli began to appear. This interval was regarded as the control value of mechanical refractory period of the preparation being tested in a medium aerated with $100 \%$ oxygen at $30^{\circ} \mathrm{C}$.

The drug used was trimetazidine dihydrochloride $[1-(2,3,4$-trimethoxybenzyl $)$-piperazine $\mathrm{HCl}$, Vastarel- $\mathrm{F}^{\circledR}$, Servier-Inabata]. Drug concentration was expressed as a percentage in the medium $(\mathrm{w} / \mathrm{v})$. Since the molecular weight is $339.33,0.1 \%(\mathrm{w} / \mathrm{v})$ of the drug approximately corresponds to $3.0(\mathrm{mM})$.

Since the changes in the length of the refractory period of atrial and papillary muscles induced by low and high temperatures and by oxygen insufficiency in the aeration gas, as well as the influence of trimetazidine on these changes, were examined, the experiment was very complicated. More than 360 animals were used. For example, in the case in which the refractory period of atrial muscle was examined for a preparation kept at $25^{\circ} \mathrm{C}$ and aerated with $20 \%$ oxygen gas (containing $80 \%$ nitrogen), firstly the temperature was lowered from 30 to $25^{\circ} \mathrm{C}$ at $60 \mathrm{~min}$ after the beginning of the stimulation ; secondly at $90 \mathrm{~min}$, the aeration gas $(100 \%$ oxygen gas) was changed for $20 \%$ oxygen gas; then $30 \mathrm{~min}$ later, at $120 \mathrm{~min}$ after the beginning of the stimulation, the determination of the refractory period was carried out. When the influence of trimetazidine on the refractory period was examined, the drug was added to the medium $30 \mathrm{~min}$ before the change of temperature, that is, $30 \mathrm{~min}$ after the beginning of the stimulation. In other words, after the beginning of the stimulation in the preparation, the addition of the drug, the changing of the temperature, the changing of the aeration gas and the determination of the refractory period of muscle were performed in succession at $30 \mathrm{~min}$ intervals. When the experimental conditions were not changed at 30,60 and $90 \mathrm{~min}$ after the beginning of the stimulation, the value of the refractory period of the muscle was regarded as the control value. Every value of the refractory period, obtained when the experimental conditions were changed, was expressed as percentage of the control value. 


\section{Results}

1. The partial pressure of oxygen in Locke's solution aerated with an oxygen-nitrogen gas mixture, at 25,30 and $40^{\circ} \mathrm{C}$

When the Locke's solution was kept at 25, 30 and $40^{\circ} \mathrm{C}$ and aerated with an oxygen-nitrogen gas mixture of various proportions $\left(100 \% \mathrm{O}_{2} ; 60 \% \mathrm{O}_{2}\right.$ and $40 \%$ $\mathrm{N}_{2} ; 40 \% \quad \mathrm{O}_{2}$ and $60 \% \quad \mathrm{~N}_{2} ; 20 \% \quad \mathrm{O}_{2}$ and $80 \% \mathrm{~N}_{2} ;$ or $10 \% \mathrm{O}_{2}$ and $90 \% \mathrm{~N}_{2}$ ), the partial pressure of oxygen in the gas, that diffused into the Locke's solution, reduced linearly with the decrease in the oxygen concentration in the aeration gas (Fig. 1).

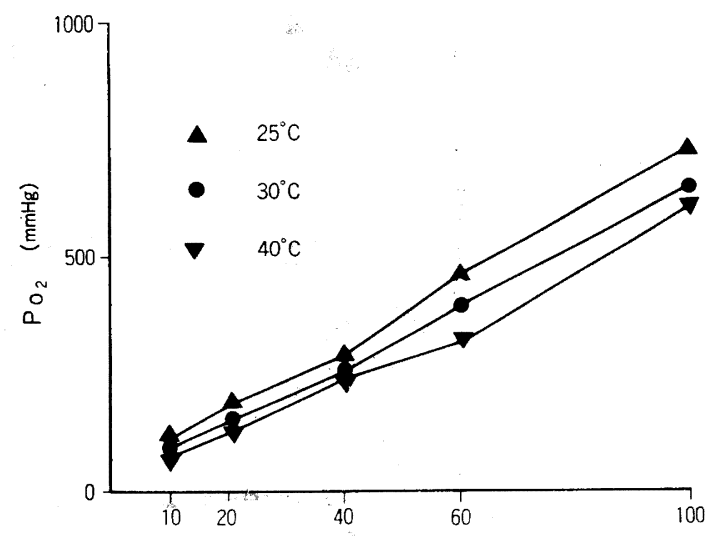

OXYGEN CONCENTRATION $(\%)$ IN AERATION GAS

Fig. 1 The partial pressure of oxygen $\left(\mathrm{Po}_{2} \mathrm{mmHg}\right)$ in the total gas contained in the Locke's solution which was aerated with oxygennitrogen gas mixtures. The gas was mixed with together in various proportions $(100 \%$ $\mathrm{O}_{2} ; 60 \% \mathrm{O}_{2}$ and $40 \% \mathrm{~N}_{2} ; 40 \% \mathrm{O}_{2}$ and $60 \%$ $\mathrm{N}_{2} ; 20 \% \mathrm{O}_{2}$ and $80 \% \mathrm{~N}_{2} ; 10 \% \mathrm{O}_{2}$ and $90 \%$ $\mathrm{N}_{2}$ ). The pressure of oxygen was estimated in the medium kept at 25,30 and $40^{\circ} \mathrm{C}$ by use of a polarographic oxygen monitor (Ohio Medical, No. 200 type).

was lengthened when the temperature was

lowered from 30 to $25^{\circ} \mathrm{C}$ and shortened when the temperature was raised from 30 to $40^{\circ} \mathrm{C}$ (Fig. 2).

When the atrial and papillary muscles were examined in a medium at 25,30 or $40^{\circ} \mathrm{C}$ and the oxygen concentration in the aeration gas was reduced from $100 \%$ to $60,40,20$ or $10 \%$, each refractory pariod generally shortened with reducing the oxygen concentration : the shortening was most marked when the atrial muscle was kept at 25,30 or $40^{\circ} \mathrm{C}$ and when the papillary muscle was kept at $40^{\circ} \mathrm{C}$; and not so marked when the papillary muscle was kept at 25 or $30^{\circ} \mathrm{C}$ (Fig. 2).

3. The influence of trimetazidine on the shortening of the refractory period of atrial and papillary muscles induced by oxygen insufficiency in aeration gas

In the presence of trimetazidine $[0.00001$ to $0.001 \%(\mathrm{w} / \mathrm{v})]$ in the medium aerated with $100 \%$ oxygen gas at 25,30 or $40^{\circ} \mathrm{C}$, the refractory period of atrial and papillary muscles was almost the same as that in the absence of the drug. In the atrial muscle kept at 25,30 or 


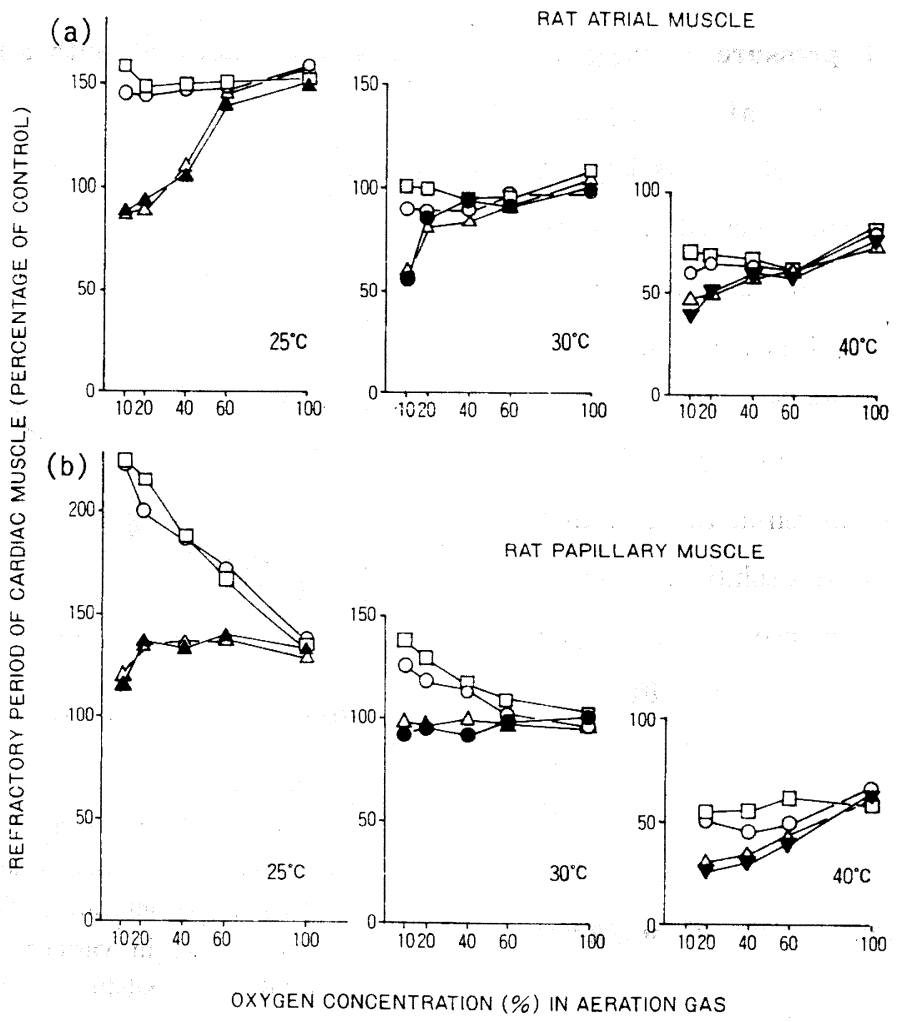

Fig. 2 Changes of the refractory period of isolated rat atrial (a) and papillary (b) muscles induced by low $\left(25^{\circ} \mathrm{C}\right)$ and high $\left(40^{\circ} \mathrm{C}\right)$ temperatures and by oxygen insufficiency in the aeration gas, and influences of trimetazidine on these changes. The refractory period was determined by use of Govier's double stimulus method, and was expressed in terms of percentage of control, which was obtained in the muscle aerated with $100 \%$ oxygen gas at $30^{\circ} \mathrm{C}$. Then, the control value in atrial muscle and that in papillary muscle are set in this study. Both driving and test stimuli were given to the muscle at a frequency of $4 \mathrm{~Hz}$. The refractory period of each muscle kept at $25^{\circ} \mathrm{C}$ ( $\boldsymbol{\Delta}-\boldsymbol{\Delta}$ ), $30^{\circ} \mathrm{C}(-\mathbf{O})$ and $40^{\circ} \mathrm{C}(\boldsymbol{\nabla}-\boldsymbol{\nabla})$ was changed by lowering the oxygen concentration in the aeration gas from $100 \%$ to $60,40,20$ and $10 \%$ : when the papillary muscle was kept at $40^{\circ} \mathrm{C}$ and aerated with $10 \%$ oxygen gas, contractile responses to electrical stimulation didn't occur. Each value is the mean of values obtained in six preparations. By the presence of trimetazidine $[(\triangle-\triangle) 0.00001 \%,(\bigcirc-\bigcirc) 0.0001 \%,(\square-\square) 0.001 \%(w / v)]$ in the medium, the refractory period was influenced.

$40^{\circ} \mathrm{C}$ and in the papillary muscle kept at $40^{\circ} \mathrm{C}$, the refractory period shortened with reducing the oxygen concentration in the aeration gas, and the shortening was prevented by the presence of the trimetazidine. In the papillary muscle kept at 25 or $30^{\circ} \mathrm{C}$, the shortening 
of the refractory period brought about by the oxygen insufficiency was not so marked, but the shortening of the refractory period was not only prevented by the trimetazidine but also lengthened to a longer degree than the refractory period obtained in the medium aerated with $100 \%$ oxygen gas at the same temperature (Fig. 2). The effect of trimetazidine $[0.001 \%$ $(\mathrm{w} / \mathrm{v})]$ was more marked than that of the drug $[0.0001 \%(\mathrm{w} / \mathrm{v})]$.

The refractory period of atrial muscle aerated with $20 \%$ oxygen gas at $25^{\circ} \mathrm{C}$ was $93.0 \pm 9.2$ $(\mathrm{n}=6$, every following is 6$)$, which was changed by addition of trimetazidine [0.00001, 0.0001 and $0.001 \%(\mathrm{w} / \mathrm{v})]$ to the medium to $88.2 \pm 5.6,143.6 \pm 12.0$ and $148.2 \pm 12.3$, respectively; when the muscle was aerated with $10 \%$ oxygen gas in place of the $20 \%$ gas, the values were in turn $88.7 \pm 7.4,86.6 \pm 6.2,145.9 \pm 16.7$ and 157.1 \pm 14 .9. In the medium kept at $30^{\circ} \mathrm{C}$, when $20 \%$ oxygen gas was used, the values were $85.1 \pm 9.2,80.7 \pm 6.8$, $88.4 \pm 5.6$ and $98.7 \pm 5.7$; when $10 \%$ oxygen gas was used, these were $55.3 \pm 4.1,61.6 \pm$ 5. $0,89.4 \pm 7.5$ and $100.2 \pm 9$. 3. In the medium kept at $40^{\circ} \mathrm{C}$, when $20 \%$ oxygen gas was used, the values were $52.2 \pm 8.5,50.8 \pm 6.4,64.5 \pm 6.3$, and $69.4 \pm 4.4$ : when $10 \%$ oxygen gas was used, these were $38.2 \pm 4.4,47.4 \pm 6.1,60.5 \pm 5.8$ and $70.1 \pm 6.8$.

The refractory period of papillary muscle aerated with $20 \%$ oxygen gas at $25^{\circ} \mathrm{C}$ was 135.4 \pm 9.2 , which was changed by the trimetazidine to $133.8 \pm 10.8,200.3 \pm 16.5$ and $213.3 \pm$ 13.3 ; when $10 \%$ oxygen gas was used, the values were $115.2 \pm 5.6,129.0 \pm 11.3,223.8 \pm$ 23. 8 and $225.5 \pm 20.5$. In the medium kept at $30^{\circ} \mathrm{C}$, when $20 \%$ oxygen gas was used, the values were $94.3 \pm 6.9,95.5 \pm 7.1,119.0 \pm 10.7$ and $129.6 \pm 12.4$; when $10 \%$ oxygen gas was used, these were $91.9 \pm 4.6,99.3 \pm 7.2,125.7 \pm 10.7$ and 138. $0 \pm 12.3$. In the medium kept at $40^{\circ} \mathrm{C}$, when $20 \%$ oxygen gas was used, these were $27.1 \pm 1.2,30.1 \pm 5.1,51.6 \pm 6.7$ and $53.9 \pm 8.1$; when $10 \%$ oxygen gas was used, contractile responses to electrical stimulation didn't occur.

The refractory period of each muscle in the presence of trimetazidine $[0.0001$ and $0.001 \%$ $(\mathrm{w} / \mathrm{v})]$ in the medium aerated with 10 and $20 \%$ oxygen gas at 25,30 and $40^{\circ} \mathrm{C}$ was significantly different from that in the absence of the drug $(P<0.005)$, except for that of atrial muscle in the presence of the drug $[0.0001 \%(\mathrm{w} / \mathrm{v})]$ in the medium aerated with $20 \%$ oxygen gas at $30^{\circ} \mathrm{C}$.

\section{Discussion}

Usually, an experiment using an isolated rat cardiac muscle is performed in a medium aerated with 95 to $100 \%$ oxygen gas at $30^{\circ} \mathrm{C}$, as in the conditions the preparation shows a function in vitro which well suggests a normal or nearly normal function of the muscle in vivo, though the body temperature of the animal in vivo is about $37^{\circ} \mathrm{C}$. An effect of a drug 
on the cardiac muscle, also, is examined in these conditions of medium.

In our previous papers ${ }^{8-9}$ ) it was reported that trimetazidine lengthened the refractory period, but a much dose of the drug such as $0.01 \%(\mathrm{w} / \mathrm{v})$ or more was required to lengthen it. The dose was too much to presume a clinical application. In the present study, also, trimetazidine $[0.0001$ or $0.001 \%(\mathrm{w} / \mathrm{v})]$ scarcely influenced the refractory period of the muscle in the medium aerated with $100 \%$ oxygen gas at $30^{\circ} \mathrm{C}$ (Fig. 2).

However, trimetazidine showed a characteristic effect on isolated rat cardiac muscle which was aerated with insufficient oxygen gas. When the concentration of oxygen in the aeration gas was reduced from $100 \%$ to $60,40,20$ or $10 \%$, the refractory period of the muscles generally shortened, and the shortening was prevented by the presence of trimetazidine in the medium : the prevention was marked when atrial muacle was kept at 25,30 or $40^{\circ} \mathrm{C}$ and papillary muscle was kept at $40^{\circ} \mathrm{C}$ (Fig. 2). When papillary muscle was kept at 25 or $30^{\circ} \mathrm{C}$, the trimetazidine not only prevented the shortening of refractory period but also even lengthened it longer than the refractory period determined in the condition without oxygen insufficiency.

In our experiment that hasn't be published yet, when the trimetazidine was replaced by ajmaline, lidocaine, quinidine or procainamide, each drug didn't give any influence on the refractory period of the muscle aerated with insufficient oxygen gas at 25,30 or $40^{\circ} \mathrm{C}$ even in the highest concentration that each drug scarcely influenced in the refractory period of the muscle aerated with $100 \%$ oxygen gas at $30^{\circ} \mathrm{C}$. Then, the effect of trimetazidine is regarded to be characteristic, as it is not remarkable on the cardiac muscle aerated with sufficient oxygen gas but remarkable on the muscle aerated with insufficient oxygen gas.

The effect of trimetazidine is presumed to be due to one of "membrane stabilizing effects" of the drug, which shows very little influence on normal function of a tissue but gives an influence on variations in function caused by physiological or chemical disturbance. The other membrane stabilizing effects of the drug were already reported in our previous papers ${ }^{3-6)}$, the prevention of suppression in spontaneous contractions of isolated guinea-pig atria caused by the effect of a potassium-free Locke's solution, a toxic dose of strophanthin-G or a low temperature medium. However, the drug concentration to shows these effects was a much dose such as $0.01 \%(\mathrm{w} / \mathrm{v})$ or more. As the concentration of trimetazidine to lengthen the refractory period of cardiac muscle aerated with insufficient oxygen gas was 0.0001 or $0.001 \%(\mathrm{w} / \mathrm{v})$, the drug effect is most sensitive of its various membrane stabilizing effects.

In this country, trimetazidine has been used as an anti-anginal drug since Schmitt introduced it in 1964, and no serious side effect of the drug has been reported from anywhere in spite of its wide clinical use during more than ten years. The experimental results obtained in this 
study suggest a new possible application of trimetazidine to the clinical field.

\section{References}

1) Schmitt, H. : Toxicological and pharmacological investigations of 4004S. Laboratoires Servier, Orleans 1964.

2) Fujita, Y. : Effects of 1-(2,3,4-trimethoxybenzyl)-piperazine dihydrochloride on the cardiovascular system in the rabbit. Japan J. Pharmacol. 17, 19 29, 1967.

3) Nagata, M., Imamura, I. and Sugimoto, J. : Anti-nicotinic action of vastarel on guinea-pig atria. Japan J. Pharmacol. 19, 628 629, 1969.

4) Sugimoto, J., Nagata, M., Fugono, R., Kotani, M. and Morita, M. : Strophanthin-G toxicity and sodium ions. Jpn. Cir. J. 34, 725 732, 1970.

5) Nagata, M., Imamura, I., Fugono, R. and Sugimoto, J. : The actions of trimetazidine on isolated guinea-pig atria. Japan J. Pharmacol. 21, 337 343, 1971.

6) Imamura, I. : The experimental pharmacologic studies on the mode of actions of trimetazidine in isolated guinea-pig atria, especially in relation to potassium ions. J. Kansai Med.Sch. 24, 33 43, 1972.

7) Govier, W.C. : The mechanism of the atrial refractory period change produced by ouabain. J. Pharmacol. exp. Ther. 148, 100 105, 1965.

8) Nagata, M., Sugimoto, J. and Morita, M. : Comparative studies on the pharmacological actions of anti-arrhythmics in isolated guinea-pig atria. Jpn. Cir. J. 37, 641 646, 1973.

9) Sugimoto, J., Nagata, M. and Morita, M. : Comparative studies on the pharmacological actions of anti-arrhythmic grugs in isolated rat papillary muscle. Clin. Exp. Pharmacol. Physiol. 5, 17 21, 1978. 